\title{
IMPACT OF VARIABLE GEOMETRY MINIFLAPS ON SAILPLANE FLIGHT CHARACTERISTICS
}

\author{
Peep LAUK ${ }^{1}$, Karl-Erik SEEGEL ${ }^{2}$, Toivo TÄHEMAA ${ }^{3}$ \\ Estonian Aviation Academy, Tartu, Estonia \\ E-mails: ${ }^{1}$ peep.lauk@eava.ee (corresponding author); ${ }^{2}$ karl-erik.seegel@eava.ee; ${ }^{3}$ toivo.tahemaa@ttu.ee
}

Received 19 October 2017; accepted 06 December 2017

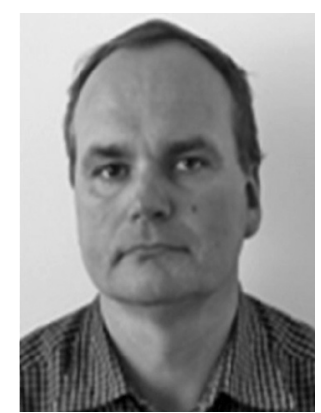

Peep LAUK, MSc

Date and place of birth: 1966, Elva, Estonia.

Education: 1989 - Estonian University of Life Sciences.

Affiliations and functions: researcher, Estonian Aviation Academy.

Research interests: sailplane and UAV aerodynamics.

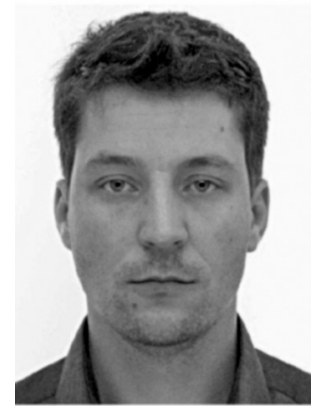

\section{Karl-Erik SEEGEL, $M S c$}

Date and place of birth: 1983, Kuressaare, Estonia.

Education: Tallinn University of Technology, Product Development.

Affiliations and functions: vice-rector for Development, Estonian Aviation Academy. Research interests: material science, aerodynamics, product development.

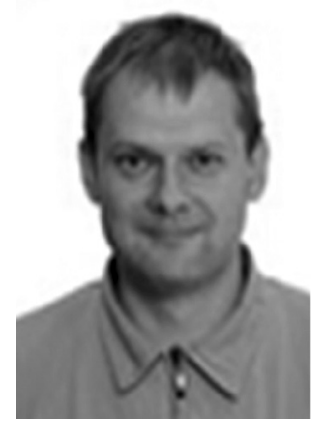

\section{Toivo TÄHEMAA, $P h D$}

Date and place of birth: 1967, Tallinn, Estonia.

Education: Tallinn University of Technology, Product Development.

Affiliations and functions: associate professor, Tallinn University of Technology.

Research interests: product development methodology.

Abstract. Miniflaps (also known as mini-TED, active Gurnay flaps, etc.) located at the wing trailing edge enable to increase wing lift and reduce the aerodynamic drag. Variable geometry miniflaps (VGMF) elaborated at the Estonian Aviation Academy enable to expand the wing area up to 6.5\%, when extended, and, at the same time, deflect 16.7 degrees downwards. The use of VGMF is especially promising for reducing the airspeed and sink speed of modern high wing loading sailplanes flying in thermals. The VGMFs were built in cooperation with the Lithuanian company JSC "Sportine Aviacija ir Ko". They were fixed inside the sailplane LAK-17B trailing flaps. During the test flights, the VGMF effect on the sailplane's sink speed was measured at different airspeeds and different flap positions. The flight parameters were recorded electronically and later calculated for standard atmosphere. The method of parallel flight was used for comparison. The results indicate that with the flaps position at +9 degrees, the CAS $79.5 \mathrm{~km} / \mathrm{h}$ sink speed decreased 
$0.775-0.555 \mathrm{~m} / \mathrm{s}$, i.e. $39.6 \%$. The sailplane's wing loading was $39.4 \mathrm{~kg} / \mathrm{m}^{2}$. With the flaps position at +15 degrees, the optimal airspeed decreased, but the sink speed, compared to the previous, rose. $\mathrm{Cl}$ max increased with the VGMF 1.41-1.58 (i.e. $12 \%$ ).

Keywords: mini-TED, miniflaps, airfoil, sailplane, L/D ratio.

\section{Introduction}

The idea of developing miniflaps for airplanes was introduced in R. Liebeck's paper (Liebeck 1978), where the experiment results of using the Gurnay flap (GF) with the Newman wing airfoil are discussed. Regardless of its low height (1.25\% of the length of the wing chord), the

GF proved to be amazingly effective for both: increasing the lift and reducing the drag. The downwash at the wing's trailing edge contributes to the GF in increasing the lift. Simultaneously, boundary layer transition separation lengthened on the wing (Jang et al. 1998), due to which the drag generated by this part of the wing can decrease (irrespective of the additional drag coefficient by the GF). The hypothesis created by Robert Liebeck that two stationary counterrotating vortices appeared behind the GF was refuted by later studies. Kai Richter's paper (Richter 2010) shows that behind the GF, as well as behind the other mini-TED, a row of separated vortices will arise - the von Karman's vortex street (Fig. 1). Dimensions of the vortex flow depend on the GF height, AoA, and Re-number. A similar vortex flow emerges also at the aft of the miniflap. With the sailplane DG1000 , the $2.2 \%$ of the length of the wing chord miniflaps were first tested by Professor Joseph Mertens of Aachen

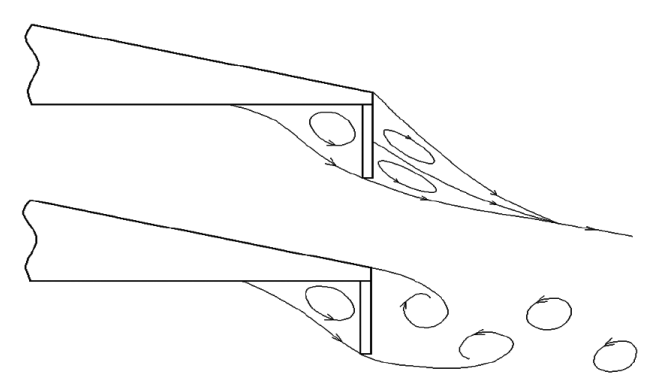

Fig. 1. Von Karman-i vortex street at the aft of the wing's Gurnay flap (Richter 2010)

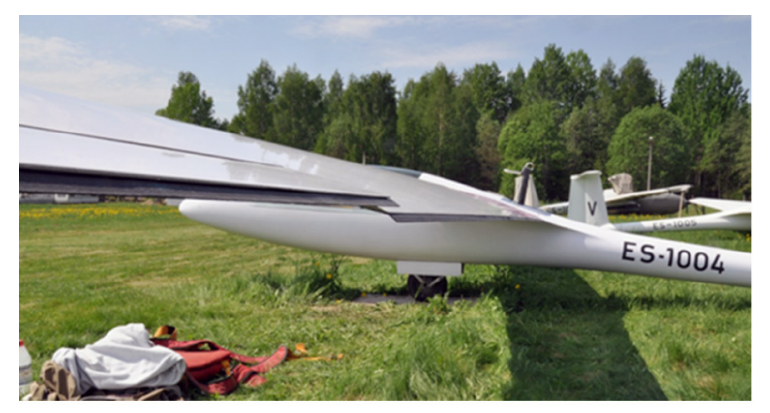

Fig. 2. Jantar-Standard 3 with the fixed $2 \%$ chord length miniflaps (Photo: K-E. Unt)
Technology University (Akademische Fliegergruppe an... 2005-2006).

According to the test results, in thermalling, the optimum miniflap deflection angles varied from +30 to +45 degrees. At landing, the best miniflap deflection angle was +90 degrees, due to the biggest drag that this angle helped to generate. The author of this paper ran flight tests with $2 \%$ length of the chord fixed deflection angle miniflaps on the Jantar-Standard 3 sailplane (Lauk, Unt 2015) (Fig. 2).

At a $+30^{\circ}$ angle of deflection, miniflaps decreased the drag $\mathrm{C}_{1}$ within ranges from 0.99 to 1.21 and from 1.32 to 1.66. At the same time, the sailplane's critical angle of attack increased 2.1 degrees. With miniflaps fixed at $+45^{\circ}$, the angle of deflection increased the lift coefficient considerably, yet they also generated greater drag. The tests revealed an interesting phenomenon: the sailplane's resistance to stalling improved. It enabled prolonged flying at an overcritical angle of attack. Furthermore, the test results implied a need for developing the miniflaps with deflection angles changeable during flight, as the miniflaps with unchangeable deflection angles increased the drag at $C_{l}<0.99$, thus, consequently also increasing the sink speed.

\section{Design}

Wing flaps improve sailplanes' flight characteristics. In thermals they are lowered, whereas in straight and speed flight they remain in the neutral position or are even deflected upward (negative position). In order to minimize the airfoil drag, the flap position shall be changed according to the speed of flying. Hereby, the most common are the non-slotted plain flaps, due to their simple structure. Today, modern sailplanes that have airfoils with a relative thickness of $12.7-13.4 \%$ enable thermal flying by applying lift coefficients of 1.4-1.5 without significantly increasing the drag. Though the Fowler flaps are more effective in generating lift because of their slot, they also generate relatively higher drag. Non-slot flaps (also referred to as Wortmann flaps) are reasonably effective for sailplanes SB-11 constructed in Akaflieg Braunchweig (Fig. 3). While extended, they contribute to the maximum lift coefficient increase of up to 1.7. Furthermore, the total wing area also expanded up to $20 \%$.

The flight characteristics of the SB-11 are better than those of other sailplanes of similar type; its sole disadvantages being lower wing torsional stiffness and complicated structure of its flap controls. The relatively thin airfoils used today, with their laminar boundary layer on the lower surface of the wing accounting for $92-95 \%$ of 
the wing chord, do not enable to use that kind of flaps, because they would interrupt the laminar boundary layer.

In order to give the variable geometry miniflaps (VGMF) their proper aerodynamic characteristics, the software XFLR 5 was used (XFLR5 Software 2015). The code XFOIL was developed by M. Drela (Drela 1989). It enabled to design more optimal VGMFs for the airfoil LAP 7-131/17 (Fig. 5). The pressure diagram is depicted in Figure 4.

A relatively low drag of the airfoil was achieved due to the long laminar boundary layer reaching $68 \%$ on the upper and $75 \%$ on the lower surface with the lift coefficient of $\mathrm{Cl} 1.75$.

With flaps deflected at +15 degrees, the VGMF at the angle of attack of 0 degrees augmented the lift coefficient by 0.669 .

VG miniflaps are embedded inside the flaps. To let the VGMF to be extended, the lower aft side was covered with a flexible precurved mylar seal. Like Fowler flaps, the VGMF, when extended, enlarge the wing surface area by $6.5 \%$, and can be deflected by 16.7 degrees (Figs 7,8 ).

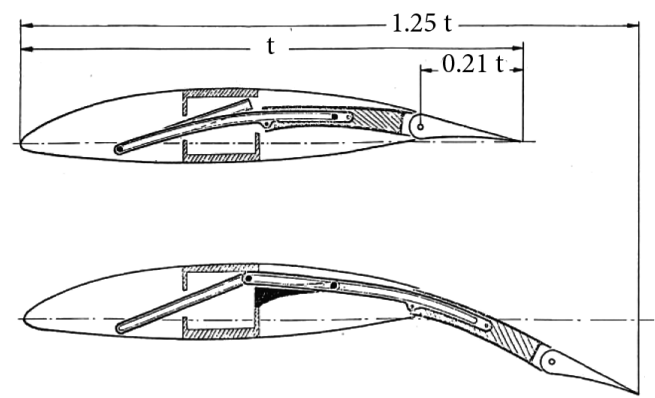

Fig. 3. SB-11 using Wortmann flaps (Horstmann, Quast 1979)

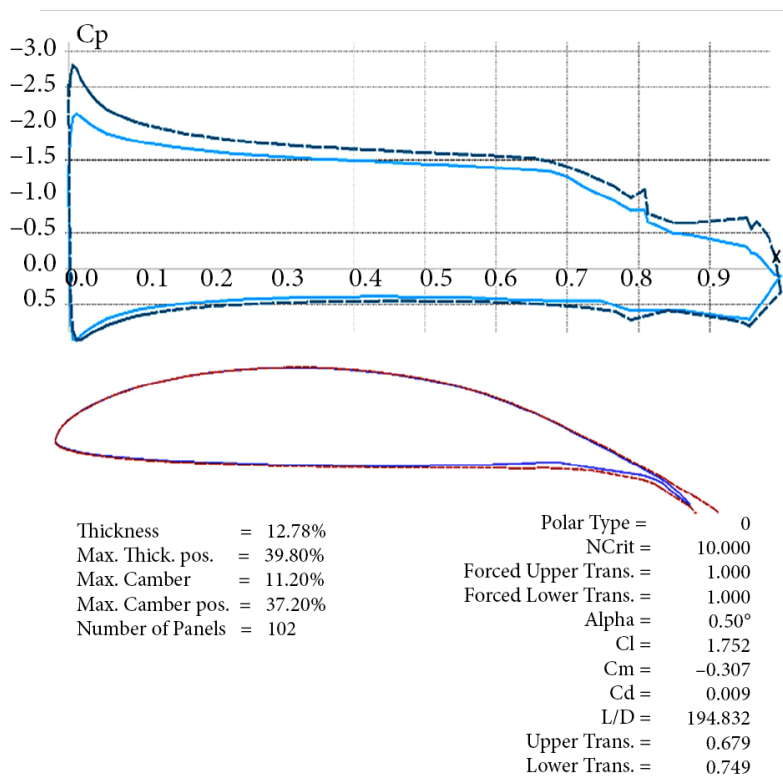

Fig. 4. Pressure distribution on the LAP 7-131/17 airfoil with a VGMF at a $\operatorname{Re} 1,1 \times 10^{6}$ (Figure: P. Lauk)

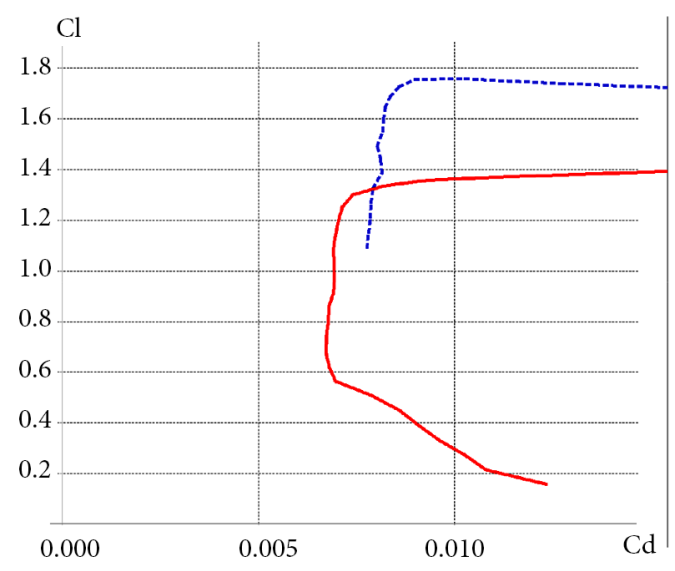

Fig. 5. Polar curves of airfoil LAP 7-131/17 with flaps at +15 deg and without the VGMF (Figure: P. Lauk)

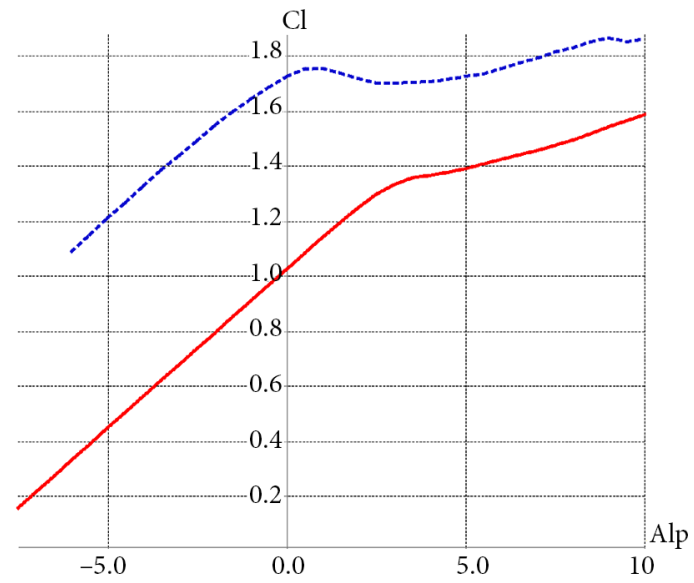

Fig. 6. Impact of the VGMF on the $\mathrm{Cl}$ and AoA of airfoil LAP 7-131/17 (Flap angle +15 deg.) (Figure: P. Lauk)

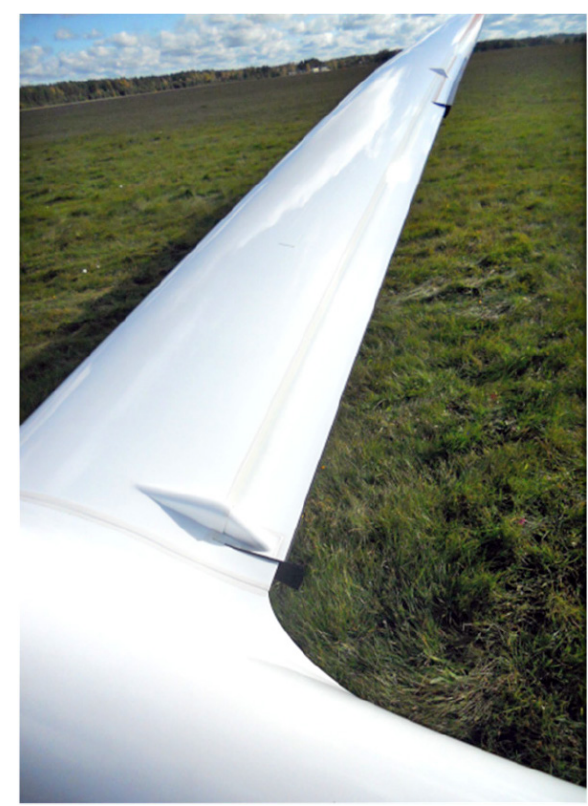

Fig. 7. VGMF extended position (Photo: P. Lauk) 
There is no slot between the wing airfoil and flap. Abroader length of flap (17\% of the chord) is needed to attach the CFRP flap track and tilt actuator mechanism inside the VGMF. By using the VGMF at a flap deflection angle of $+15^{\circ}$, the wing's maximum lift coefficient increased from 1.36 to 1.75 , i.e. $28.5 \%$, whereas the critical angle of attack decreased from 3.5 to 0.5 degrees (Fig. 6). For the optimal lift distribution on the wing, alongside actuating the flaps and VGMFs, it is also necessary to deflect the ailerons. Hereby, it is necessary to deflect the ailerons downwards at an angle that exceeds the angle of the flaps.

From the engineering point of view, the design of the control mechanism for VGMFs is a serious challenge, because the wings of the sailplanes bend greatly during flight, yet the coherence of wing deflection and actuator operation have to be maintained (Fig. 9).

The torsional stiffness of the flaps will not be affected, and its center of mass should stay within reasonable bounds. To enhance the rigidity, an extra spar and ribs were added to the flap structure.

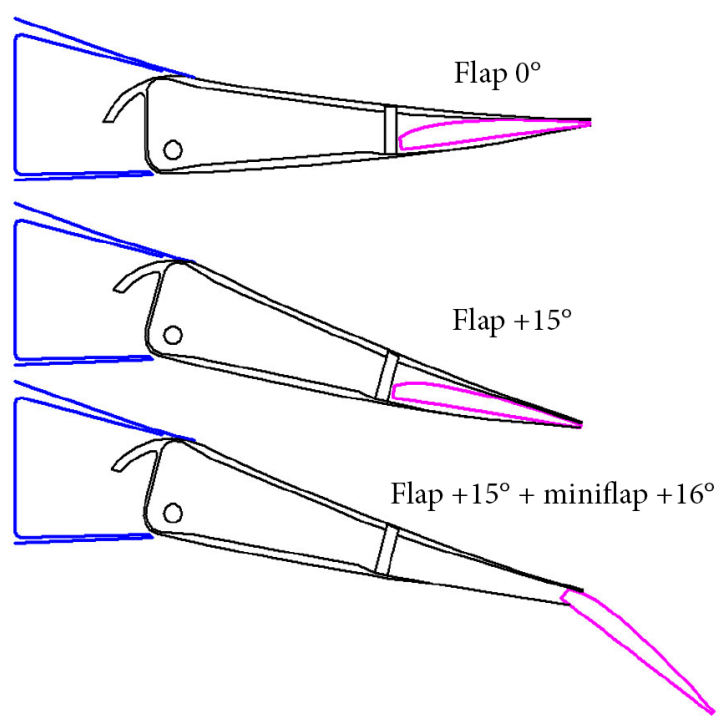

Fig. 8. Different positions of the VGMF in sailplane LAK-17B (Figure: K-E. Seegel)

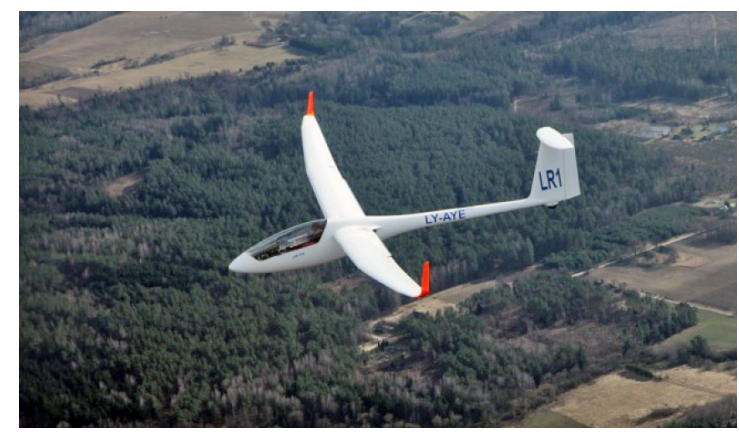

Fig. 9. LAK-17B with the VGMF performing a test flight (Photo: P. Lauk)
To minimize weight, the CFRP panels were sandwiched using a $1.5 \mathrm{~mm}$ balsa sheet. The miniflaps were designed at the Department of Aircraft Engineering of the Estonian Aviation Academy (Fig. 10). Most of the miniflap control elements were milled from aluminum alloy 7075. Several smaller elements were made from stainless steel $316 \mathrm{R}$ by using metal $3 \mathrm{D}$ sintering in the Powder Metal Laboratory at Tallinn University of Technology (Fig. 11).

The linkage inside the wing is actuated using the 8x1 CFRP tube close to the flap edge (Figs 12 and 13).

The lower aft side of the flaps is coated with elastic precurved mylar sealing (Fig. 14).

With the wings rigging, the controls of the miniflaps automatically joined the fuselage controls. It turned out that the new flaps with the miniflaps constructed

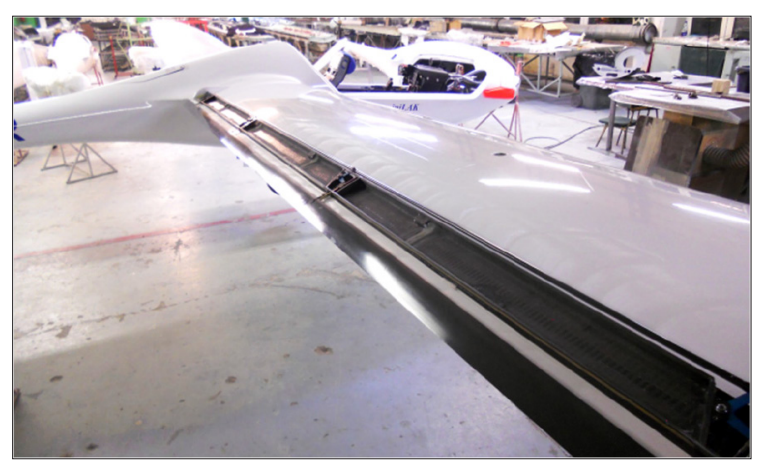

Fig. 10. VGMF control mechanism for the flaps (Photo: P. Lauk)

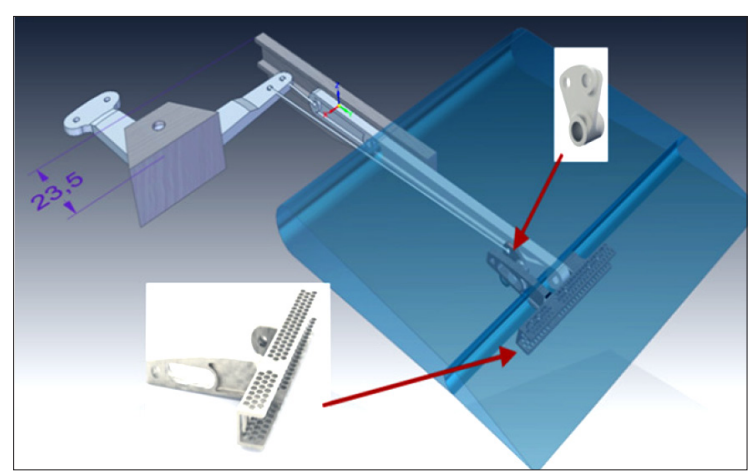

Fig. 11. 3D printed elements inside the miniflaps (Photo: K-E. Seegel)

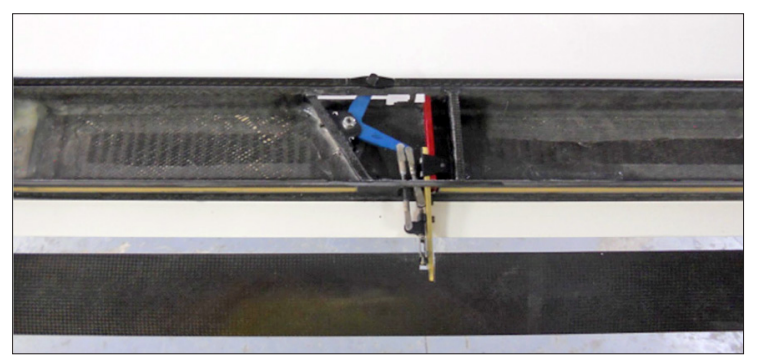

Fig. 12. The control mechanism with the miniflaps in the extended position (Photo: P. Lauk) 


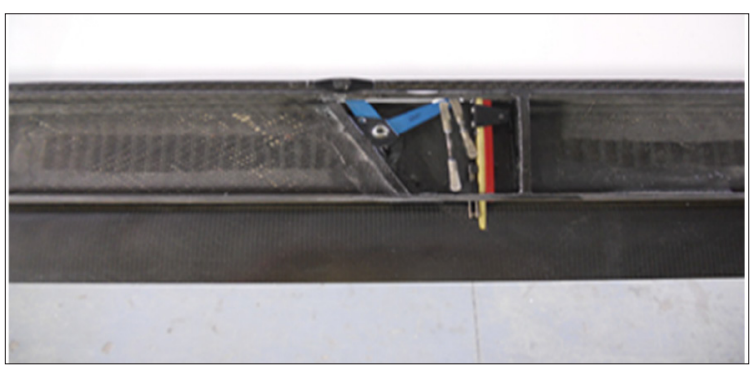

Fig. 13. The control mechanism with the miniflaps in the retracted position (Photo: P. Lauk)

weighed 142 grams (7\%) less on average, compared with the weight of the (original) flaps initially. Also, their center of gravity was located near to the rear limit. With their torsional stiffness being lower than that of the original flaps, the sailplane's maximum allowed speed was reduced to $180 \mathrm{~km} / \mathrm{h}$. Also, the new flaps being lighter in weight, enabled to increase the thickness of the CFRP skin laminates and, thus, to achieve the relevant torsional stiffness. Actuation of the miniflaps is controlled in the cockpit by using a dedicated lever. Prior to test flights, NDT was performed. To do this, the miniflaps adjoined to the flaps were subjected to a $3 \mathrm{G}$ force load. Both, deflection and dihedral/torsional angle of the flaps were measured. Likewise, the operation of the mechanical parts under loads was tested. The VGMF location in a sailplane is shown in Figure 15.

\section{Methodology}

In flight tests, the methodology developed by Richard Johnson was used (Johnson 1989) together with the Hendrix flight data recorder (Hendrix 2011). Before test flights, the airspeed indicator was calibrated using the Marchiori Air Data Test Set MPS 43. Likewise, airspeed system calibration data received in preceding test flights by implementing the DFS-60 static probe were used. The results received are presented in Figure 16.

During test flights, the LX Eos flight recorder was used for data measuring and recording. The data obtained was processed and analyzed using the AJ1.IGC Software (IGC Software 2017). The program enables to reproduce and analyze the received flight data in 3D.

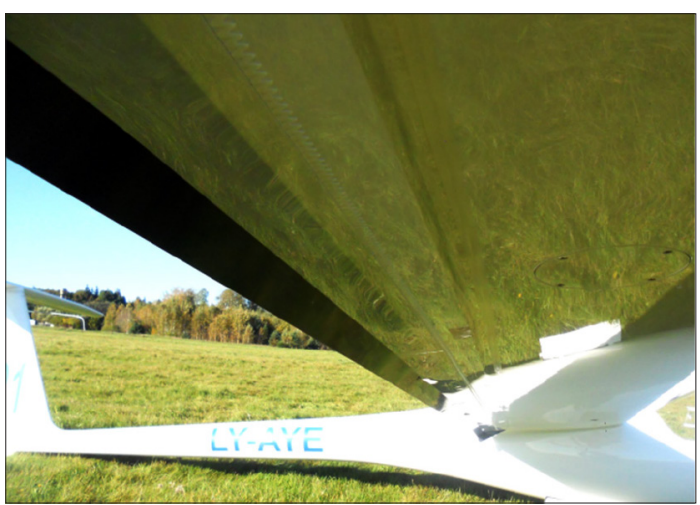

Fig. 14. The miniflaps are in the extended position with the precurved mylar seal coating them at the underside of the wing's trailing edge (Photo: P. Lauk)

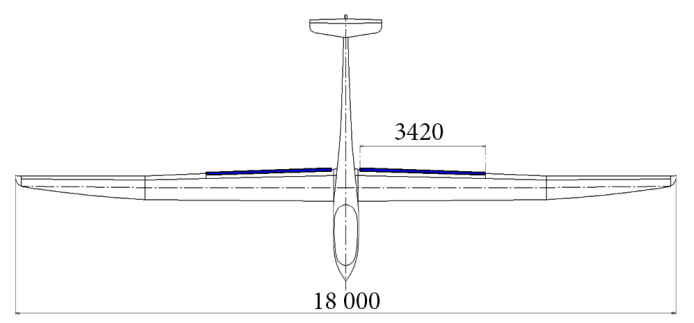

Fig. 15. The VGMF in sailplane LAK-17B (Figure: K-E. Seegel)

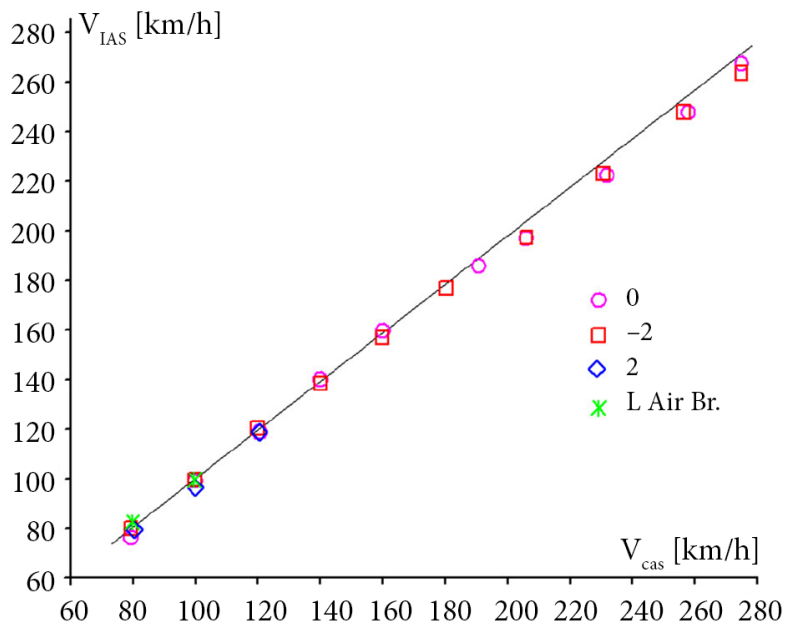

Fig. 16. Test flight results provided by the calibrated airspeed indicator (Figure: K-E. Seegel)

Table 1. Corrected results of the test flights (Table: P. Lauk)

\begin{tabular}{|c|c|c|c|c|c|c|c|}
\hline \multirow{2}{*}{ LAK-19T } & CAS km/h & 76.4 & 78.3 & 80.4 & 84.6 & & \\
\hline & $\mathrm{Vy} \mathrm{m} / \mathrm{s}$ & 0.940 & 0.744 & 0.643 & 0.577 & & \\
\hline \multirow{2}{*}{ LAK-17B flap+15 } & CAS km/h & 76.7 & 78.1 & 80.2 & 82.0 & 84.8 & 87.9 \\
\hline & $\mathrm{Vy} \mathrm{m} / \mathrm{s}$ & 1.088 & 0.892 & 0.737 & 0.628 & 0.590 & 0.594 \\
\hline \multirow{2}{*}{$\begin{array}{l}\text { LAK-17B } \\
\text { flap+9 +VGMF }\end{array}$} & CAS km/h & 74.8 & 76.4 & 79.5 & 83.2 & & \\
\hline & $\mathrm{Vy} \mathrm{m} / \mathrm{s}$ & 1.092 & 0.803 & 0.555 & 0.660 & & \\
\hline \multirow{2}{*}{$\begin{array}{l}\text { LAK-17B } \\
\text { flap+15+VGMF }\end{array}$} & CAS km/h & 72.6 & 74.1 & 76.4 & 79.0 & & \\
\hline & $\mathrm{Vy} \mathrm{m/s}$ & 1.115 & 0.805 & 0.638 & 0.692 & & \\
\hline
\end{tabular}


Moreover, in the cockpit a GoPro camera was used to measure the sailplane's pitch angle and to shoot a video of flying at different air speeds. For parallel flying, airplanes with similar flight characteristics were used; but mostly the sailplane LAK-19 T was used, which always received thorough pre-flight calibration. Before test flights, the TOW of the sailplane was estimated and (additional) weight was loaded to the tail ballast tank so as to shift the CG to the possible rear position. During flight testing, the wing loading of both sailplanes was $39.39 \mathrm{~kg} / \mathrm{m}^{2}$.

For testing, the sailplane was towed to an altitude of $2500 \mathrm{~m}$ above the ground. During the glide flight, sink speed was measured at different airspeeds and also by using different positions of flaps and miniflaps. The flight at each leg at a constant speed lasted 180 seconds. In parallel flying, the sailplanes remained spread out at 30-50 meters from each other. The difference between the sink speeds was compared. Measurement was stopped when rising above the inversion layer, and the measurement results were adjusted, based on the variance of air pressure and temperature readings with those of the standard atmosphere. For calculations, the following formulae were used (Pätzold 2014):

$$
\begin{aligned}
& E\left(V_{C A S}\right)=\frac{\sqrt{V_{C A S}^{2}-V_{y}^{2}}}{V_{y}}\left(\approx \frac{V_{C A S}}{V_{y}}=\frac{C_{L}}{C_{d}}\right) ; \\
& C_{L}=\sqrt{\frac{2 m g}{q S V_{C A S}^{2}} ;} \\
& C_{D}=\frac{E}{C_{L}} ; \\
& E=L / \text { D ratio. }
\end{aligned}
$$

Here $V_{\text {cas }}$ is the calibrated airspeed $(\mathrm{m} / \mathrm{s}) ; V_{y}-\operatorname{sink}$ speed $(\mathrm{m} / \mathrm{s}) ; m$ - glider flight weight; $g$ - gravity of Earth $\left(9.80665 \mathrm{~m} / \mathrm{s}^{2}\right) ; q$ - density of air sea level $\left(1.225 \mathrm{~kg} / \mathrm{m}^{2}\right)$; $S$ - wing area $\left(\mathrm{m}^{2}\right) ; C_{d}-$ drag coefficient; $C_{L}-$ lift coefficient.

$$
\left(C_{d}-C_{d i, e l l i p}\right)=C_{d}-\frac{C_{L}^{2}}{\pi \Lambda} .
$$

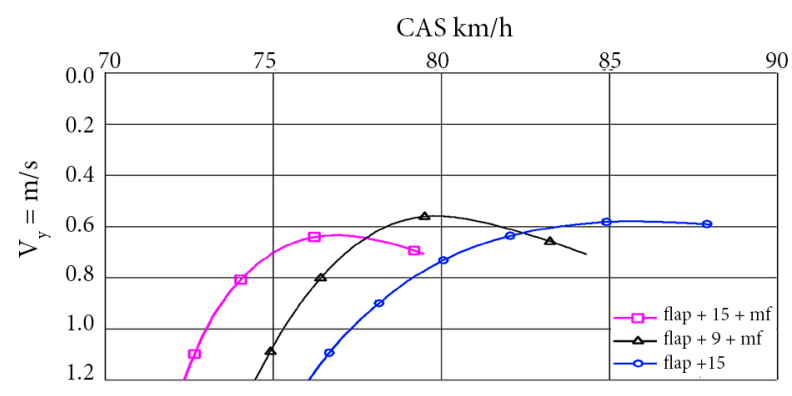

Fig. 17. VGMF impact on LAK-17B sink speed at different flap positions (Figure: P. Lauk)
Here $C_{d i}$ is the induced drag coefficient and $A$ - the aspect ratio. The corrected results of the test flights are represented in the Table 1.

\section{Results}

During the test flights at an airspeed of $72-82.5 \mathrm{~km} / \mathrm{h}$ the variable geometry miniflaps decreased the sink and stall speed of the LAK-17B sailplane (Fig. 17).

The flaps were deflected at $+9^{\circ}$ and $+15^{\circ}$; the ailerons were deflected at the same time at $+14.4^{\circ}$ and $+21.2^{\circ}$. With the flap angle at +9 degrees and at an airspeed of $79.5 \mathrm{~km} / \mathrm{h}$, by using the VGMF, the sink speed was decreased from 0.775 to $0.555 \mathrm{~m} / \mathrm{s}$, i.e. $39.6 \%$. With the flaps deflection angle at +15 degrees, the optimal flight speed decreased but the sink speed rose. One factor leading to the aerodynamic drag increase was the canal between the flap(s) and the fuselage that thwarted the elliptic lift distribution on the wing flap angles, thus inducing the growth of interferential drag.

Unlike the narrow (e.g. 2\% length of the chord) miniflaps; those making up $6.5 \%$ of the length did not increase the critical angle of attack but, rather, decreased the critical angle of attack by 3 degrees (Fig. 14). Indeed, the decrease of the lift at an overcritical angle of attack by using the miniflaps was relatively slow, and the decrease in the critical angle of attack, likewise, was relatively negligible. Yet, the sailplane's lateral stability decreased, because, during stall, the lift force decrease/the drag was higher near the ailerons.

Due to the impact of the miniflaps, the maximum increase in the lift coefficient $C_{1}$ increased from 1.41 to 1.58 , i.e. $12 \%$, and the stall speed decreased from 75.4 to $72 \mathrm{~km} / \mathrm{h}$, i.e. $4.7 \%$. The aerodynamic efficiency of the miniflaps was reduced by their small area in conparison with the wing surface area. It accounted for $45 \%$ of the total area of the wing. If the miniflaps were located along the whole wing's trailing edge from root to tip, the lift coefficient could possibly exceed $32 \%$, which would enable a reduction of the stall speed by $13.8 \%$. At a flight speed in excess of $82.5 \mathrm{~km} / \mathrm{h}$, i.e. $C_{l}<1.2$, the miniflaps increased the drag, it is, therefore, advised to keep them retracted into the flaps when flying for competition. Several pilots tested the use of miniflaps in thermal flights. Dependent on each pilot's weight, a 35-40 degree bank angle flight was performed at an airspeed of $80-85 \mathrm{~km} / \mathrm{h}$ $\left(39 \mathrm{~kg} / \mathrm{m}^{2}\right)$, which is considerably lower than this sailplane's designed flight speed, i.e. $90-100 \mathrm{~km} / \mathrm{h}$. The effect of using the VGMF is explicitly felt when flying in narrow thermals.

Prior to test flights, additional weight was loaded to the tail ballast tank. By changing the centre of gravity to $26-35 \%$, the sailplane's straight flying characteristics improved, while its stall speed decreased. However, an additional change of the centre of gravity up to $39.9 \%$ did 
not lead to further augmentation of the sailplane's flight characteristics. Instead, its stall characteristics deteriorated. Yet, its lateral stability could be improved somewhat when reducing the ailerons' deflection angle by $1-2$ degrees.

\section{Conclusions}

Alongside modeling with the program XFLR5, the implementation of VGMFs helped to improve the aerodynamic characteristics of LAK-17B sailplane within the range of $C_{l} 1.2-1.58$. At the same time, the critical angle of attack decreased by 3 degrees. The factor accounting for the biggest $\mathrm{L} / \mathrm{D}$ value was the use of miniflaps (reaching up to 39.8 at $C_{L}$ of 1.29). The effectiveness of miniflaps could still be higher, if, instead of $45 \%$, they could impact up to $65-75 \%$ of the wing area.

\section{Future work}

VGMF effectiveness can be further enhanced. To that end, a fairing-like transition ought to be designed between the fuselage and miniflaps. The formation of slots and stupendous surfaces ought to be avoided, as they reduce the effectiveness of VGMFs. Also, the trailing edge flaps of the next series should have greater torque stiffness. Both, commercial and military planes with high wing loading (700-850 kg/m²) could highly benefit from using the miniflaps. Miniflaps enable to reduce the wave drag at Mach 0.72-0.82 and $C_{l}$ 0.65-0.8 (Richter 2010). In long-range airplanes, the use of miniflaps would account for fuel economy in the range of $6-8 \%$. Further research could be conducted on the effect of the miniflaps deflection angle of 45-60 degrees, first and foremost, to improve the airplane's handling of stall. Poor stall characteristics will disfavor the implementation of the NLF airfoil, because with a laminar-flow airfoil, the use of wing leading edge slats will be complicated.

\section{Acknowledgements}

The authors extend their heartfelt gratitude to Mr. Lauri Kollo, PhD, of Tallinn Technological University for his assistance provided with the $3 \mathrm{D}$ sintering of the miniflaps' metal elements. Heartfelt thanks are also due to Mr. Vytautas Sabeckis, President of Lithuanian Gliding
Federation, for his support with organizing the test flights. Last but not least, the authors are deeply indebted to Mr. Vytautas Maciulis, CEO of "Sportine aviacia ir Ko", sailplane manufacturing company, for his unreserved help with constructing the VGMF and organizing the test flights.

\section{References}

Akademische Fliegergruppe an der Universität Karlsruhe e. V. Jahresberisht [online]. 2005-2006 [cited 15 May 2014]. Available from Internet: http://www.akaflieg.uni-karlsruhe. de/vp-content/uploads/2015/03/2005-2006.pdf

Drela, M. 1989. XFOIL: an analysis and design system for low Reynolds number airfoils, in Proceedings of the Conference Notre Dame Indiana, June 5-7 1989. New York: Springer Verlag, 1989, 1-12. https://doi.org/10.1007/978-3-642-84010-4_1

Hendrix, J. 2011. Measuring glider performance with flight data recorder [online], [cited 12 April 2011]. Available from Internet: http:www.deturbulator.com/measuring-gliderperformance.pdf

Horstmann, K. H.; Quast, A. 1979. Wing profile design of the world championship sailplane SB-11, in Nasa Technical Memorandum NASA TM-75829 19800022879.

IGC Software [online]. 2017 [cited 10 May 2017]. Available from Internet: http// www.igssoftware.com

Jang, S. C.; Ross, J. C.; Cummings, R. M. 1998. Numerical investigation of an airfoil with a Gurnay flap, Aircraft Design 1(2): $75-88$. https://doi.org/10.1016/S1369-8869(98)00010-X

Johnson, R. H. 1989. Sailplane performance flight test methods, Soaring Magazine 1989(May): 26.

Lauk, P.; Unt, K.-E. 2015. Influence of miniflaps on sailplane flight characteristics, Aviation 19(3): 105-111. https://doi.org/10.3846/16487788.2015.1104793

Liebeck, R. 1978. Design of subsonic airfoil for high lift, Journal of Aircraft 15(9): 547-561. https://doi.org/10.2514/3.58406

Pätzold, F. 2014. Vorläufige Ergebnisse der Flugleistungsvermessung der Lak-17a (S5-3117) im Vergleichflugverfahren in Aalen-Heidenheim-Elchingeni 20./21. August 2012. Techniche Univärsität Braunschweig, Institut für Flugfürung 21.02.2014.

Richter, K. 2010. Untersuchungen zur Aerodynamik von Miniature Trailing-Edge Devices in transsonischen Strömungen. DLR Deutches Zentrum für Luft- und Raumfahrt e.V, Forschungsberichte 09/2010 [online], [cited 20 May 2014]. Available from Internet: http// elib.dlr.de/65260/ (in German).

XFLR5 Software [online]. 2015 [cited 15 November 2015]. Available from Internet: http://www.xflr5.com/xflr5.htm 